\title{
A ATRIBUIÇÃO DO ACENTO NOS ADVÉRBIOS EM-MENTE NO PORTUGUÊS: DISCUSSÃO DE ASPECTOS PROSÓDICOS E RÍTMICOS
}

\author{
Thais Holanda de ABREU-ZORZI* \\ Gladis MASSINI-CAGLIARI**
}

- RESUMO: Este artigo objetiva apresentar uma discussão a respeito do comportamento prosódico dos advérbios em -mente no Português Arcaico (PA) e no Português Brasileiro (PB) sob o viés das Fonologias Prosódica e Métrica. Para a descrição do estatuto prosódico desses advérbios, sobretudo no PA, elegeram-se como corpus as 420 cantigas em louvor à Virgem Maria, conhecidas como Cantigas de Santa Maria (CSM), e as 1251 cantigas profanas (510 de amigo, 431 de escárnio e maldizer e 310 de amor). Por outro lado, elegeu-se como corpus de estudo do PB um recorte do banco de dados do "Corpus Online do Português", elaborado em conjunto pelos pesquisadores Michael Ferreira, da Universidade de Georgetown, e Mark Davies, da Brigham Young University. A partir da coleta e da análise dos advérbios em -mente nos corpora, concluiu -se que tais advérbios são, do ponto de vista prosódico, compostos (um acento lexical e um secundário), tanto em PA como em PB, visto que podem ser considerados estruturas que são formadas por partes independentes entre si, em que a Regra de Atribuição do Acento atua em domínios distintos: nas bases já flexionadas e no "sufixo"-mente.

- PAlAVRAS-CHAVE: Advérbios em -mente. Atribuição do acento. Prosódia. Português Arcaico. Português Brasileiro.

\section{Introdução}

Neste artigo $^{1}$ apresenta-se um estudo comparativo $^{2}$ das formas adverbiais em mente em duas sincronias da língua portuguesa - Português Arcaico (doravante, PA) e

\footnotetext{
Universidade Estadual Paulista (UNESP), Faculdade de Ciências e Letras, Araraquara, São Paulo, Brasil. thaishabreu@ bol.com.br. ORCID: 0000-0001-6716-7057

** Universidade Estadual Paulista (UNESP), Faculdade de Ciências e Letras, Departamento de Linguística, Araraquara, São Paulo, Brasil. gladis@fclar.unesp.br. ORCID: 0000-0002-4050-7645

1 Este artigo é uma retomada de parte da tese de Abreu-Zorzi (2016), intitulada O estatuto prosódico dos advérbios em-mente: um estudo comparativo entre Português Arcaico e Português Brasileiro, orientada pela Prof. ${ }^{\text {a }}$ Dr. ${ }^{\text {a }}$ Gladis Massini-Cagliari.

2 Deve-se ressaltar que este trabalho não se constitui um estudo de cunho sociovariacionista, uma vez que não foi realizado um estudo quantitativo das formas encontradas, mas qualitativo de comparação entre as formas da mesma
} 
no Português Brasileiro (PB) a fim de observar e descrever possíveis mudanças com relação ao estatuto prosódico dessas formas. A partir da descrição e análise dos dados por meio das Fonologias Prosódica e Métrica, chegou-se à conclusão de que tais advérbios são portadores de dois acentos (um lexical e um secundário), como poderá ser constatado na seção de descrição dos resultados. O acento lexical é o acento atribuído no momento de formação de uma palavra e, por esse motivo, é chamado também de acento de palavra. $\mathrm{O}$ acento secundário é uma proeminência prosódica que pode ocorrer ou por efeito das regras de eurritmia da língua - uma sequência muito longa de sílabas átonas não é aceitável em Português e, por isso, algumas dessas sílabas passam a ter um reforço extra (MASSINI-CAGLIARI; CAGLIARI, 2001, p.114), em palavras como "Àraraquára" ou "Pìndamònhangába" - ou por fatores lexicais (morfológicos) em derivados dos sufixos -íssim(o,a), -mente e -zinh(o,a).

Portanto, o foco deste trabalho incidiu sob a tentativa de delimitar o status fonológico e prosódico de formas linguísticas (no caso, os advérbios em -mente) de um período da língua portuguesa no qual não é mais possível encontrar falantes nativos vivos (PA) e, a partir disso, descrever se ocorreram mudanças relacionadas ao estatuto prosódico dessas formas na sincronia atual.

Devido à dificuldade em se trabalhar com fenômenos fonológicos (no caso a atribuição do acento nos advérbios em -mente) do período arcaico da língua portuguesa, utilizamo-nos como corpus do PA textos poéticos metrificados, a citar as cantigas profanas (510 de amigo, 431 de escárnio e maldizer e 310 de amor) e as 420 cantigas religiosas em louvor à Virgem Maria, denominadas Cantigas de Santa Maria (CSM). Segundo alguns pesquisadores do período arcaico do português (MASSINI-CAGLIARI, 1995; MATTOS E SILVA, 2006), estes tipos de textos são os mais ricos para o estudo da prosódia de uma língua e seus dados, pois nos revelam "pistas" sobre o acento e o ritmo de um período do português do qual não temos registros orais dos falantes da época, possibilitando, assim, a descrição de fenômenos de natureza prosódica.

Dessa forma, a metodologia do trabalho em questão partiu da escansão do poema em sílabas poéticas, na qual podemos ver os limites das sílabas fonéticas. Por exemplo: por meio da escansão poética e da definição dos limites das sílabas fonéticas pode-se localizar os acentos poéticos e, consequentemente, o acento nas palavras, facilitando a investigação de sua estrutura prosódica e permitindo - no caso das formas adverbiais em -mente - formular hipóteses a respeito de esses nomes serem, no período arcaico do português, derivados (um acento lexical) ou compostos (dois acentos lexicais).

Para o mapeamento das formas adverbiais nas Cantigas de Santa Maria foi utilizada a versão de Mettmann (1986-1988-1989). As cantigas religiosas foram mandadas compilar pelo Rei Sábio de Castela, Afonso X no século XIII e chegaram até nós através de quatro manuscritos antigos (denominados “códices”). Para as Cantigas de Escárnio

palavra em períodos diferentes do Português. Sendo assim, foram comparados dados qualitativamente e não corpora, dadas as especificidades de cada um desses. 
e Maldizer, utilizamos a versão de Lapa (1998). Tais cantigas chegaram até nós por meio de dois manuscritos antigos. Um deles é o Cancioneiro da Biblioteca Nacional de Lisboa, conhecido também pelas abreviaturas B ou CBN e denominado antigamente de Cancioneiro Colocci Brancuti. O outro manuscrito é o Cancioneiro da Vaticana, conhecido pelas abreviaturas V ou CV. Por fim, as Cantigas de Amor foram extraídas dos três Cancioneiros: Cancioneiro da Ajuda (A ou CA), edição fac-similada de 1994, Cancioneiro Colocci Brancuti (B) e Cancioneiro da Vaticana (V); as de amigo foram extraídas de B, na edição fac-similada de 1982.

Por outro lado, a escolha para o corpus em PB foi feita devido ao fato de o banco de dados do Corpus do Português ${ }^{3}$ apresentar diversos textos escritos no Brasil e em Portugal, de diversas fontes e gêneros, de literários a jornalísticos.

O Corpus do Português foi elaborado em conjunto pelos pesquisadores Michael Ferreira, da Universidade de Georgetown, e Mark Davies, da Brigham Young University. É constituído de mais de 45 milhões de palavras em quase 57 mil textos portugueses de diversas fontes, desde as literárias até as jornalísticas, que abarcam o período de 1300 até o final do século XX. Sendo assim, reúne uma variedade muito grande de temas, gêneros e enfoques, que permitem uma investigação mais abrangente sobre os fenômenos fonológicos do português atual. No entanto, durante o mapeamento das formas adverbiais nesse corpus, não foi possível encontrar ocorrências de formas adverbiais em -mente em contexto poético. Dessa forma, optou-se, em um segundo momento, pela utilização de alguns exemplos de ocorrências desses advérbios no PB, extraídos de uma coletânea de poemas da literatura de cordel.

A coletânea escolhida foi uma edição crítica de Lopes (1982), editada pelo Banco do Nordeste, que apresenta a análise de vinte e dois clássicos da literatura de cordel, com autoria de dezesseis cordelistas distintos. Segundo Lopes (1982), a literatura de cordel pode ser definida como uma poesia narrativa, com temas populares e impressa em folhetos. Resquícios desse tipo de literatura foram encontrados inicialmente na Alemanha dos séculos XV e XVI, em folhetos avulsos que traziam, em forma de versos para serem cantados, informações sobre os acontecimentos da época. Ao observar as informações trazidas por Lopes (1982), percebe-se que a nossa opção, em um segundo momento, pelo corpus da literatura de cordel foi acertada, uma vez que, desde a sua origem, esse tipo de literatura apresentava uma relação entre poesia e música, fato este que, como já se sabe, favorece um estudo de cunho prosódico como é o caso do trabalho apresentado neste artigo.

\footnotetext{
Fala-se em "recorte" do banco de dados, pois este banco foi utilizado apenas para a checagem dos advérbios em -mente mapeados em PA, a fim de saber se ocorreu alguma mudança nas duas sincronias da língua portuguesa: a origem (PA) e a atual. Sendo assim, não foram mapeadas todas as ocorrências de advérbios em -mente encontradas neste corpus do PB; apenas checou-se a forma adverbial atual em comparação com a forma antiga mapeada para descrever possíveis mudanças.
} 


\section{Breves considerações sobre Fonologia Prosódica e palavra fonológica}

A Fonologia Prosódica é uma teoria fonológica não linear que trabalha com uma organização hierárquica dos constituintes prosódicos. Diferentemente do que ocorria na fonologia gerativa padrão de Chomsky e Halle (1968), na qual as descrições fonológicas caracterizavam-se por uma organização linear dos segmentos, na teoria prosódica a organização dos constituintes prosódicos em níveis hierárquicos consegue explicar o caráter gradiente do acento, ou seja, a capacidade de este apresentar diversos graus de proeminência. Como exemplo dos vários graus de proeminência que uma palavra pode apresentar, pensemos em PB no vocábulo pós-graduação, no qual se observa uma proeminência no prefixo pós e duas proeminências na palavra graduação, uma representada pelo acento primário na sílaba ção e outra (de natureza eurrítmica) localizada na sílaba $d u$, caso a sequência $d u$ - $a$ seja silabada como um hiato, ou gra, caso essa sequência seja silabada como ditongo, conforme mostra o esquema a seguir:

(1) pós + graduação = pós-gra.dù.a.ção

pós + graduação $=$ pós-grà.dua.ção

A partir dessa nova dimensão nos estudos linguísticos (organização dos constituintes prosódicos em níveis hierárquicos), Selkirk (1980) foi quem iniciou os estudos de Fonologia Prosódica. Outro trabalho de renome da autora foi o publicado em 1984, que traz uma versão mais aprimorada de seu estudo de 1980.

Selkirk (1980) inicia seu texto afirmando que o intuito de seu estudo é apresentar uma teoria que leve em consideração uma organização suprassegmental hierárquica para o enunciado, não um simples arranjo linear de segmentos. A partir disso, a autora expõe as categorias prosódicas que podem existir nas línguas, organizando-as em hierarquias (quadro 1):

Quadro 1 - Constituintes prosódicos segundo proposta de Selkirk (1980)

\begin{tabular}{|l|l|l|}
\hline \multicolumn{3}{|c|}{ Proposta de Selkirk (1980) } \\
\hline constituintes & tradução & símbolos \\
\hline $\begin{array}{l}\text { phonological } \\
\text { utterance }\end{array}$ & enunciado fonológico & U \\
\hline intonational phrase & grupo entoacional & I \\
\hline phonological phrase & grupo fonológico & $\Phi$ \\
\hline phonological word & palavra fonológica & $\omega$ \\
\hline foot & pé & $\Sigma$ \\
\hline syllable & sílaba & $\sigma$ \\
\hline
\end{tabular}

Fonte: Massini-Cagliari (1995, p.102). 
O elemento na hierarquia prosódica dos constituintes que destacaremos é a Palavra Prosódica ou Palavra Fonológica (®), elemento este de grande importância para o nosso estudo, uma vez que é a partir da delimitação de $\omega$ que conseguimos descrever o estatuto das formas adverbiais em -mente, como será observado na seção de análise dos dados. Selkirk (1980) afirma que no nível da palavra prosódica o que é levado em consideração é a proeminência do acento.

A autora dedica um capítulo de seu trabalho de 1984 ao acento de palavra no inglês, estudando esse suprassegmento tomando como base o conceito, retirado de Siegel (1974), de afixos neutros (neutral) e não neutros (nonneutral) ${ }^{4}$ dessa língua.

Outros estudos que abordam a palavra prosódica são os de Vigário (2007, 2003, 2001). Segundo Vigário (2003), quando falamos sobre Palavra Prosódica (®), devese destacar ainda que esta pode subdividir-se em dois tipos: a Palavra Prosódica Mínima - a qual é dotada de apenas um acento primário e composta por estruturas incorporadas (palavras com sufixos ou hospedeiros mais enclíticos) ou estruturas adjungidas (palavras com prefixos ou hospedeiros mais proclíticos) - e a Palavra Prosódica Máxima ou Composta - a qual é formada por duas Palavras Prosódicas (caso das palavras compostas que não formam um sintagma fonológico), entretanto tem apenas um elemento proeminente que carrega a proeminência principal desse domínio. No caso dos advérbios estudados, essa proeminência principal se localizaria no elemento -mente.

As palavras prosódicas máximas subdividem-se em 6 tipos:

i) compostos morfossintáticos e algum composto sintático (palavra + palavra), como por exemplo, salto alto [[salto]W[alto]W]PWMAX, verde-água [[verde]W[água $]$ W]PWMAX

ii) palavras derivadas com sufixos que constituem domínios de acento independentes de sua base, como francamente [[franca]W[mente]W]PWMAX;

iii) palavras derivadas com prefixos acentuados, como em pré-estréia [[pré] W[estréia]W]PWMAX;

iv) composto morfológicos (raiz+raiz), como socioeconômico [[sócio]W[econômico] W]PWMAX;

v) estruturas mesoclíticas, como falar-te-ei [[falar-te]W[ei]W]PWMAX; (vi) abreviações, como em $C D[[$ se $] \mathrm{W}[$ de]W]PWMAX;

vii) sequência de Palavras Prosódicas consistindo de (a) pares de nomes de letras, como em $R N$ [[erre]W[ene]W]PWMAX; (b) nome de letras seguidas por numerais, como em $P$-dois [[pe]W[dois]W]PWMAX; e (c) alguns numerais seguidos por palavras frequentes horas e anos, como em onze horas [[onze]W[horas]W]PWMAX.

Considerando-se os subtipos apresentados anteriormente, verifica-se que os advérbios focalizados em nosso estudo (advérbios em -mente) enquadram-se no subtipo

Esses conceitos serão mais bem discutidos na seção de descrição e análise dos dados, a partir dos exemplos dos advérbios mapeados no PA e no PB.

5 Em seu trabalho de 2001, Vigário afirma apenas que as construções salto-alto e verde-água não se comportam claramente como compostos, e nada aborda sobre o conceito de palavra prosódica máxima. 
II: palavras derivadas com sufixos que constituem domínios de acento independentes de sua base, como será visto na seção de análise dos resultados.

Portanto, é possível compreender que a palavra fonológica ( $\omega$ ) é um constituinte extremamente importante para o tema desenvolvido neste artigo, pois o fator determinante para saber quando se está diante uma $\omega$ é a presença de um domínio acentual independente, ou seja, a presença de um acento primário de palavra. Ao definir o número de palavras fonológicas nas ocorrências mapeadas nas cantigas medievais, é possível classificá-las em formas simples ou compostas, determinando, assim, o estatuto prosódico dos advérbios em -mente no Português.

\title{
A Fonologia Métrica e as regras de atribuição do acento
}

Além de enfatizar os elementos que constituem uma sílaba, o modelo métrico trabalha ainda com fenômenos rítmicos, como o acento. De acordo com Hayes (1995, p.8, tradução nossa), a afirmação central da teoria métrica é a de que o acento é uma manifestação linguística da estrutura rítmica:

\begin{abstract}
A afirmação central da teoria métrica do acento, discutida em Liberman 1975 e Liberman e Prince 1977, é que o acento é uma manifestação linguística da estrutura rítmica. Isto é, nas línguas acentuais, cada enunciado tem uma estrutura rítmica que atua como uma estrutura de organização para a realização fonética do enunciado fonológico. Uma razão para supor que o acento é ritmo linguístico é que o padrão acentual exibe paralelos ${ }^{6}$ formais com estruturas rítmicas extralinguísticas como aquelas encontradas na música e no verso. ${ }^{7}$
\end{abstract}

Considerando que o acento pode ser definido como uma manifestação linguística da estrutura rítmica, Hayes (1995), embasado em Liberman (1975) e Liberman e Prince (1977), afirma que a teoria métrica postula que o acento não é um traço, mas sim um constituinte que pode ser representado em uma estrutura rítmica hierarquicamente organizada, uma vez que as línguas podem apresentar propriedades do acento que indiquem uma hierarquia. É o caso, por exemplo, da propriedade de distribuição rítmica (Rhythmic Distribution), que propõe que os acentos em uma sequência tendem

\footnotetext{
6 fato de o padrão acentual apresentar paralelos formais com estruturas rítmicas extralinguísticas (música, versos) é algo que pode ser observado também nos trabalhos para o PA de Massini-Cagliari (1995, 2005) e Daniel Soares da Costa $(2006,2010)$ e que auxilia na determinação do estatuto prosódico das formas adverbiais em - mente no momento de origem da língua portuguesa.

7 Original: "The central claim of metrical stress theory, argued in Liberman 1975 and Liberman and Prince 1977, is that stress is the linguistic manifestation of rhythmic structure. That is, in stress languages, every utterance has a rhythmic structure which serves as an organizing framework for that utterance's phonological and phonetic realization. One reason for supposing that stress is linguistic rhythm is that stress patterns exhibit substantial formal parallels with extra-linguistic rhythmic structures, such as those found in music and verse." (HAYES, 1995, p.8).
} 
a ocorrer em uma distância igual, criando padrões alternados e, ainda, a propriedade hierárquica do acento, na qual se observa que a maioria das línguas apresenta vários graus de acento: primário, secundário, terciário, entre outros.

Hayes (1995) apresenta ainda alguns tipos de regra de acento. O primeiro deles se refere à noção de acento fixo e acento livre. O primeiro apresenta localização previsível e deriva de alguma regra, como o acento em Espanhol, que é limitado às três últimas sílabas das palavras, enquanto que o segundo não apresenta localização previsível e é atribuído lexicalmente.

O segundo tipo de regra de acento é aquele que distingue acento rítmico de acento morfológico. $\mathrm{O}$ acento rítmico é baseado em fatores puramente fonológicos, como o peso silábico, e o acento morfológico é aquele que elucida a estrutura morfológica de uma palavra.

De acordo com Hayes (1995), há dois tipos de sistemas de acento morfológico: (1) o sistema de acento morfológico semelhante ao do inglês, no qual o acento principal é atribuído no nível do radical e a maioria dos afixos é subordinada a este acento principal, e (2) o sistema no qual o acento morfológico é resultado de uma interação complexa entre o tipo de radical (acentuado x não acentuado) e as propriedades dos afixos (afixos que podem ser inerentemente acentuados ou desacentuados, afixos que podem remover acentos dos domínios dos quais eles podem ser atribuídos, afixos que podem atribuir um acento à sílaba precedente).

Por fim, o terceiro tipo de regra de acento apresentado por Hayes (1995) é aquele que leva ou não em consideração a fronteira de palavra, por isso também chamado de Bounded e Unbounded Stress [acento limitado e ilimitado]. No sistema de acento limitado, os acentos são atribuídos dentro de uma determinada distância da fronteira de palavra ou de outro acento, como é o caso do acento de radical do inglês. Por outro lado, no sistema de acento ilimitado, os acentos podem cair em uma distância ilimitada a partir da fronteira ou outro acento, desde que tenham condições apropriadas para isso. Um exemplo desse sistema, segundo Hayes (1995), é o seguinte: a atribuição do acento pode ocorrer na sílaba mais pesada à direita da palavra. Se não é considerado o peso silábico ${ }^{8}$, o acento recai na sílaba inicial.

Ao observar os tipos de regras de acento apresentados por Hayes (1995), percebese que tanto a noção de acento rítmico quanto a de morfológico são importantes para o tema abordado neste artigo. Na formação dos advérbios em -mente pode-se observar a interação citada por Hayes (1995), na qual -mente, que é um "afixo" (utilizando termos morfológicos tradicionais) recebe acento na penúltima sílaba por razões rítmicas e ao se unir a uma base (em todos os casos mapeados, uma palavra pronta, como em "fremosamente" - exemplo (3), em que o caráter "pronto", ou seja, já flexionado, da primeira base pode ser comprovado pela presença da marca de feminino singular), pode manter o acento da base ou deslocá-lo, como será visto com mais detalhes na próxima seção.

O peso silábico é atribuído a partir da noção de sílabas pesadas (-) x sílabas leves (־). 


\section{Os advérbios em -mente: aspectos rítmicos}

O intuito desta seção é realizar uma análise dos dados encontrados durante o mapeamento das formas adverbiais em -mente nas cantigas medievais, a citar as cantigas de Santa Maria, as de escárnio e maldizer, as cantigas de amor e também as cantigas de amigo, totalizando 175 ocorrências. Além disso, juntamente com os dados das cantigas medievais, são apresentados exemplos comparativos extraídos do Corpus do Português, os quais trazem ocorrências da sincronia atual.

A descrição e análise dos dados do PA foi iniciada com a divisão das ocorrências de advérbios em -mente em dois grupos: as ocorrências que mantêm o acento da base ao se adjungir-mente (grupo 1) e as ocorrências que deslocam este acento (grupo 2), como é possível verificar a seguir:"

(2)
Grupo 1
abertamente
afficadamente
alongadamente
apostamente
apressurosamente
avondadamente
brevemente
certamente
compridamente
cruamente
dereitamente
devotamente
enganosamente
esforçadamente
espessamente
falsamente
feramente
firmemente
fortemente
francamente
fremosamente
inteiramente
ligeiramente

(3)

\section{Grupo 2}

comũalmente

lealmente

mortalmente

naturalmente

sotilmente

Massini-Cagliari $(2015,2005,1999,1995)$ considera que o acento proparoxítono é raríssimo no PA, não podendo, inclusive, ser encontrado no corpus das cantigas de amigo. Reforçando os resultados alcançados anteriormente pela autora, não foram encontradas bases proparoxítonas na formação de advérbios em -mente no corpus considerado como base para esta pesquisa. 

malamente
maravillosamente
mederosamente
omildosamente
onrradamente
ousadamente
primeyramente
quitamente
ricamente
saborosamente
seguramente
simpremente
soberviosamente
verdadeyramente
vergonnosamente
vilanamente

Os exemplos mostram que a maioria das ocorrências mapeadas nas Cantigas Medievais pertence ao Grupo 1, advérbios que mantêm o acento da base. Observa-se a seguir a escansão de algumas delas como forma de comprovar a manutenção de tal acento na base.

(4)

Cantiga de Santa Maria 205, versos 7-11

“Ca/a/ques/tas/ du/as/cou/sas |fa/zen/ mui/con/pri/da/men/te 3-5-7| 1-3-5-7 ga/a/nnar/ a/mor/ e/ gra/ça $\mid$ de/la/, se/ de/vo/ta/men/te $1-3-5-7 \mid 1-5-7$ se/ fa/zen/ e/ co/mo/ de/ven; e/ a/ssi/ a/ber/ta/men/te 2-5-7| 1-3-5-7 $\mathrm{pa} / \mathrm{re} / \mathrm{ce} / \mathrm{a} / \mathrm{ssa} / \mathrm{ver} / \mathrm{tu} / \mathrm{de}$ | so/bre/ to/d'o/me/ coi/ta/do. $\quad 2-5-7 \mid 1-3-4-7$ O/ra/çon/ con/ pi/a/da/de | o/e/ a/ Vir/gen/ de/ gra/do..." $\quad 1-3-5-7 \mid$ 1-4-7

(METTMANN, 1988, p.251).

(5)

Cantiga de Santa Maria 341, versos 55-58

“Des/que/a/ques/t' ou/ve/ di/to, | lo/g' an/te/to/da/ a/gen/te 1-4-5-7|1-2-4-7 so/biu/ en/ci/ma/ da/ pe/na, | cor/ren/do/ es/for/ça/da/men/te, 2-4-7| 2-6-8 e/di/ss'a/mui/gran/des/vo/zes:|“Ma/dre/da/quel/que/non/men/te, 2-5-7|1-4-7 $\mathrm{val} /$ - me/, ca/ tu/ sen/pre/ va/les | a/os/ que/ tor/to/ non/ fa/zen." 5-7| 1-4-7

(METTMANN, 1989, p.191). 
(6)

Cantiga de Santa Maria 309, versos 35-36

“E/ po/ren/ te/ ro/gu' e/ man/do | que/ di/gas/ a/ es/ta/ gen/te

$\mathrm{de} / \mathrm{Ro} / \mathrm{ma} /$ que/ mia/ ei/gre/ja $\mid \mathrm{fa} / \mathrm{çan} / \mathrm{lo} / \mathrm{go} / \mathrm{man} / \mathrm{te} /$ nen/te

$2-5-7 \mid 1-3-5-7$

$\mathrm{u} / \mathrm{vi} / \mathrm{ren} / \mathrm{me} /$ an/t' a/gos/to $\mathrm{ca} /$ er/ ne/v' es/pe/ssa/men/te,

$2-5-7 \mid 2-3-5-7$

ca/a/ly/ quer/o/meu/Fi/llo | Jhe/su/-Cris/t, e/ Deus/ seu/ Pa/dre. 3-4-6-7|2-3-5-7

(METTMANN, 1989, p.115).

No exemplo (4), constatam-se três ocorrências com advérbios em -mente: compridamente, devotamente e abertamente, todas em posição de rima. Segundo Massini-Cagliari e Cagliari (1998), as palavras em posição de rima são portadoras do acento mais forte do verso. Logo, ao observar a metrificação do verso no qual essas ocorrências aparecem, tem-se o acento mais forte na última sílaba poética men, como mostrou o exemplo anterior. Verifica-se ainda por meio deste exemplo que todos os versos apresentam sete sílabas poéticas e que as tônicas na maioria deles recaem em 1-3-5-7. Para a marcação das tônicas foram seguidos os preceitos de versificação do período, estabelecidos a partir da leitura da Poética fragmentária e dos manuais consultados, para auxiliar na escansão dos versos. Um fato muito interessante verificado aponta para a existência de duas proeminências prosódicas nessas ocorrências, uma vez que por meio da metrificação percebe-se que as tônicas recaem sempre na quinta e na sétima sílabas poéticas. Isto significa que nos versos em que se encontram os advérbios em -mente tais tônicas estão na mesma posição da palavra (compridamente, devotamente e a bertamente), ou seja, as duas proeminências localizam-se em -mente e na palavra que serviu de base para a formação do advérbio.

Comparando as informações obtidas a partir do trabalho de Daniel Soares da Costa (2010) com a escansão dos versos em que aparecem os advérbios em questão, percebe-se que, nas ocorrências focalizadas, os acentos das bases derivacionais (comprida, devota e aberta) foram mantidos, mesmo após a adjunção do elemento -mente. O mesmo ocorreu nos exemplos (5) e (6), com as palavras esforçadamente e espessamente, as quais mantiveram o acento de suas bases, respectivamente, nas sílabas ça e pe.

Sendo assim, tomando como base Hayes (1995), essas ocorrências do grupo 1 fariam parte do sistema de acento rítmico, visto que as bases formadoras das ocorrências do grupo 1 são todas paroxítonas terminadas em sílaba leve (padrão de acentuação dos não nomes do PA, segundo MASSINI-CAGLIARI, 1999) e, por isso, tendem a atrair o acento para a penúltima sílaba da palavra.

Deve-se destacar ainda que, como o acento da base dessas ocorrências não sofre choque acentual com o acento do elemento - mente, não há necessidade do deslocamento do acento da base. Logo, pode-se inferir que as ocorrências do grupo 1 (que mantêm o acento da base) são portadoras de dois acentos lexicais: o da base e o da forma mente. Isto indica que cada uma dessas partes constitutivas dos advérbios em -mente 
seria uma palavra fonológica distinta, fato este que será discutido com mais detalhes na próxima seção.

Para o PB, observa-se situação semelhante com algumas ocorrências encontradas nos poemas da literatura de cordel. Vejamos alguns exemplos:

(7)

$$
\begin{array}{ll}
\text { "As/ da/mas/ da/ al/ta/ côr/te } & 2-5-7 \\
\text { tra/ja/vam/ de/cen/te/men/te } & 2-5-7 \\
\text { tô/da/ cor/te im/pe/ri/al } & 1-3-6 \\
\text { es/pe/ra/va im/pa/ci/en/te } & 1-3-5-7 \\
\quad[. . .] " &
\end{array}
$$

(LIMA apud LOPES, 1982, p.28).

(8)

$\begin{array}{ll}\text { "No/di/a/ se/guin/te a/ voz } & 2-5-7 \\ \mathrm{da} / \text { la/go/a/ no/va/men/te } & 3-5-7 \\ \text { di/sse a/ Jo/ão/: te/ pre/pa/ra } & 1-4-7 \\ \quad \ldots] & \\ \text { pe/ço/ por/ fa/vor/ não/dur/mas } & 1-5-7 \\ \text { fa/ças/ por/ ser/ di/li/gen/te". } & 1-4-7\end{array}$

(SILVA apud LOPES, 1982, p.7).

Nos exemplos (7) e (8), constatam-se duas ocorrências com advérbios em mente: decentemente e novamente, todas em posição de rima. Verifica-se, por meio destes exemplos, que a maior parte dos versos apresenta sete sílabas poéticas e que as tônicas, na maioria deles, recaem em 1-3-5-7, ou seja, é favorecido um padrão rítmico alternante. Observa-se também que a escansão em sílabas poéticas nos aponta para a existência de duas proeminências prosódicas nessas ocorrências, uma vez que, recaindo as sílabas tônicas na maioria das vezes em 5 e 7 , as duas proeminências localizam-se em -mente e na palavra que serviu de base para a formação do advérbio (decentemente e novamente).

Com a escansão realizada, percebe-se ainda que, nas ocorrências os acentos das bases derivacionais (decente e nova) foram mantidos, mesmo após a adjunção do elemento-mente.

Passemos agora à análise das formas adverbiais do grupo 2 (as que deslocam o acento da base), iniciando pela metrificação de tais ocorrências: 
(9)

Cantiga de Santa Maria 247, versos 36-39

“A/ques/to/viu/ben/a/gen/te | mui/ gran/de/que/ y/es/ta/va, $2-4-5-7 \mid 1-2-5-7$ que/ to/da/co/mu/nal/men/te $\mid S a n / \mathrm{ta} / \mathrm{Ma} / r i / \mathrm{a} / \mathrm{lo} / \mathrm{a} / \mathrm{va}$ que/ tal/ mi/ra/gre/ fe/ze/ra; $\mid e / \mathrm{a} / \mathrm{mo} / \mathrm{ça} / y / \mathrm{fi} / c a / v a$ $\mathrm{va} / \mathrm{rren} / \mathrm{do} / \mathrm{sem} / \mathrm{pr}$ 'a/ei/gre/ja $\mathrm{co} / \mathrm{mo} / \mathrm{lle} / \mathrm{fo} / \mathrm{ra} / \mathrm{man} / \mathrm{da} / \mathrm{do} . " 2-4-7 \mid 1-4-7$

(METTMANN, 1988, p.346).

Cantiga de amor 307, versos 31-35

$\begin{array}{cl}\text { “Por/que/ sol/ di/zer/ a/ gen/te } & 2-3-5-7 \\ \text { do/ que/ a/ma/le/al/men/te: } & 2-3-5-7 \\ \text { «se/s'én/ non/ quer/ en/fa/dar, } & 1-3-4-7 \\ \text { na/ci/ma/gua/lar/don/pren/de,» } & 2-4-6-7 \\ \text { a/m'eu/ e/ sir/vo/ por/ en/de.” } & 2-4-7\end{array}$

(MICHAËLIS DE VASCONCELOS, 1904, p.614-615).

Nos exemplos (9) e (10), observam-se duas ocorrências com advérbios formados pelo elemento -mente: comuãlmente (correntemente) e lealmente. Ao consultar o trabalho de Daniel Soares da Costa (2010) juntamente com as escansões realizadas acima, percebe-se que em tais ocorrências o acento das bases derivacionais (comuã e leál) não foi mantido após a adjunção de -mente, embora estas bases formadoras desses advérbios sejam oxítonas, terminadas por sílaba travada (sílaba com consoante) e, portanto, atraiam o acento lexical para si.

O que ocorreu nas escansões anteriores foi um deslocamento do acento para a sílaba anterior devido ao choque acentual (stress clash) do acento da base com o acento do elemento -mente. Ao fazer algumas reflexões a respeito disso, pode-se inferir que, se ocorreu um choque acentual, é porque na verdade, em um primeiro momento, o acento das bases foi mantido e, por questões de eurritmia da língua, deslocado em um segundo momento. Sendo assim, pode-se afirmar que as ocorrências do grupo 2 deslocam o acento da base justamente porque, em um primeiro momento, mantêm tal acento e, por questões rítmicas (choque acentual), acabam por deslocá-lo. Fato semelhante ocorre no PB, como já mostraram os trabalhos de Lee (1995) e Basílio (2006); é possível observar essa semelhança de comportameto em ocorrências de advérbios em -mente extraídas de alguns poemas da já citada coletânea da literatura de cordel. 


$\begin{array}{ll}\text { "Cho/ran/do/ di/zi/a/ e/la } & 2-5-7 \\ \text { oh!/ meu/ Deus/, oh!/ pai/ cle/men/te } & 1-3-5-7 \\ \text { tra/zei/ con/fôr/to e/ con/sô/lo } & 1-4-7 \\ \text { a/ u/ma/ po/bre i/no/cen/te } & 2-4-7 \\ \text { que/ sem/ fa/zer/ mal/ a/ nin/guém } & 2-5-8 \\ \text { vi/ve a/ so/frer/ cru/el/men/te". } & 1-4-5-7\end{array}$

(MELO apud LOPES, 1982, p.376).

$\begin{array}{ll}\text { “Com/ } / \mathrm{ssa} / \mathrm{ra} / \mathrm{pa} / \mathrm{zi} / \mathrm{a} / \mathrm{da} & 2-5-7 \\ e ́ / \mathrm{que} / \mathrm{an} / \mathrm{do} \mathrm{a} / \mathrm{tu} / \mathrm{al} / \mathrm{men} / \mathrm{te} & 1-3-5-7 \\ \text { o/ mais/ fra/co/ do/ meu/ gru/po } & 1-3-7 \\ \text { bri/ga/ com/ dez/ e/ não/ sen/te". } & 1-4-7\end{array}$

(SILVA apud LOPES, 1982, p.411).

Os exemplos (11) e (12) mostram duas ocorrências com advérbios formados pelo elemento -mente: cruelmente e atualmente. Com as escansões realizadas acima, percebe-se que em tais ocorrências o acento das bases derivacionais (cruéle atuál) não foi mantido após a adjunção de-mente, embora estas bases formadoras desses advérbios sejam oxítonas, terminadas por sílaba travada (sílaba com consoante) e, portanto, atraiam o acento lexical para si. Sendo assim, pode-se dizer que a formas adverbiais do grupo 2, tanto em PA quanto em PB, podem ser realizadas foneticamente com dois acentos: um lexical, na sílaba men, e outro secundário, em alguma das sílabas da base.

O acento secundário, segundo Massini-Cagliari e Cagliari (2001), é uma proeminência prosódica que pode ocorrer ou por efeito das regras de eurritmia da língua ou por fatores lexicais. No caso dos advérbios enfocados neste estudo, o acento secundário ocorre por fatores lexicais (como foi visto pelo exemplo das palavras do grupo 2), pois a ocorrência de tal acento é dada pela estrutura morfológica da palavra, no momento de formação desses advérbios. Já o acento secundário por eurritmia (acento secundário rítmico) ocorre, pois:

Como, em português, uma seqüência muito longa de sílabas átonas não é aceitável, algumas dessas sílabas passam a ter um reforço extra, formando uma onda rítmica mais regular. Dessa forma, a ocorrência de acentos secundários pode ser considerada um efeito de regras de eurritmia da língua. (MASSINI-CAGLIARI; CAGLIARI, 2001, p.114).

Sobre o acento secundário, Costa (2010) afirma ainda que, quando há o encontro de dois acentos em PA, o sistema linguístico dessa fase da língua portuguesa prefere um padrão binário, ou seja, "os acentos secundários ocorrem em um intervalo bastante 
regular, a cada segunda sílaba" (COSTA, 2010, p.179). E é justamente isso que se observa nos exemplos do grupo 2, como na palavra lealmente. Percebe-se que o acento secundário recai sobre a segunda sílaba antes da tônica, ou seja, na sílaba le. Nessa formação o acento secundário não é realizado foneticamente sobre o acento da própria base, uma vez que, originalmente, o acento da base se encontra na sílaba al. Devido ao choque acentual entre o elemento -mente e o acento de palavra da base na sílaba $a l$, há o deslocamento da posição do acento desta sílaba para a sílaba le.

A fim de melhor ilustrar algumas questões relacionadas ao deslocamento ou não do acento ocorrido das formas adverbiais mapeadas nos corpora, passemos agora à representação de algumas delas, tanto as do grupo 1 (advérbios que mantêm o acento da base), quanto as do grupo 2 (advérbios que deslocam o acento da base), por meio das grades métricas parentetizadas. Comecemos pelas ocorrências do grupo 1, em que as proeminências da linha 0 representam, ao mesmo tempo, o pé que dá suporte ao acento principal, gerado pela regra de acento principal, não iterativa, e, com relação à primeira palavra, também os pés que dão suporte às proeminências secundárias, contruídas a partir de uma regra iterativa (COLLISCHONN, 1994).

\begin{tabular}{|c|c|c|c|c|}
\hline ( & & & $\mathrm{x}$ & ) \\
\hline ( & $\mathrm{x}$ & ) & (x & ) \\
\hline (x) & (x & .) & (x & .) \\
\hline a & ber & ta & men & te \\
\hline
\end{tabular}

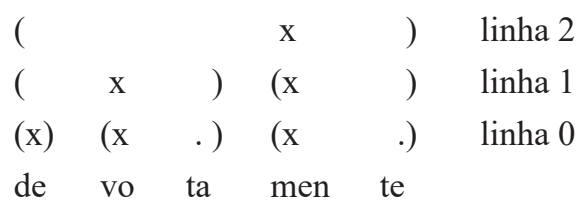

$\begin{array}{lccccc}( & & & \mathrm{x} & ) & \operatorname{linha} 2 \\ ( & \mathrm{x} & ) & (\mathrm{x} & ) & \operatorname{linha} 1 \\ (\mathrm{x}) & (\mathrm{x} & .) & (\mathrm{x} & .) & \operatorname{linha} 0 \\ \text { es } & \text { pe } & \text { ssa } & \text { men } & \text { te } & \end{array}$

Os exemplos anteriores mostram que na linha 0 tem-se o nível do pé, na linha 1 o nível da palavra e na linha 2 o nível que se estabelece a proeminência entre as bases. A linha 1 particularmente é importante para este estudo, uma vez que é nela que se observa a presença de duas palavras distintas, com acentos independentes. Por serem ocorrências do grupo 1, constata-se ainda na linha 1 que os acentos das bases foram 
mantidos em cada uma das ocorrências expostas, uma vez que não há necessidade de deslocamento, já que não ocorre colisão acentual.

Observemos a partir deste momento as grades parentetizadas de algumas das ocorrências do grupo 2:

(16)

a.

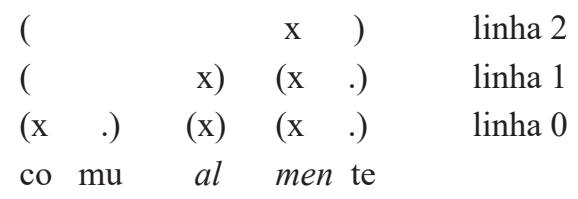

b.

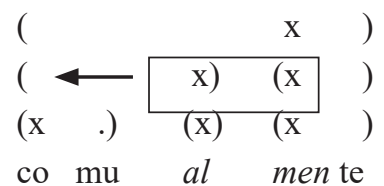

c.

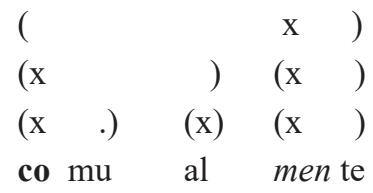

(17)

a.

$\begin{array}{lllll}( & & \mathrm{x} & ) & \text { linha 2 } \\ ( & \mathrm{x}) & (\mathrm{x} & ) & \text { linha 1 } \\ (\mathrm{x}) & (\mathrm{x}) & (\mathrm{x} & .) & \text { linha 0 } \\ \text { le } & \text { al } & \text { men } & \text { te } & \end{array}$

b.

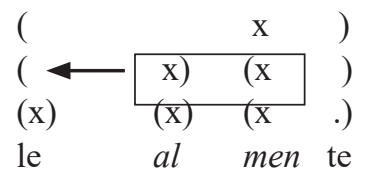

c.

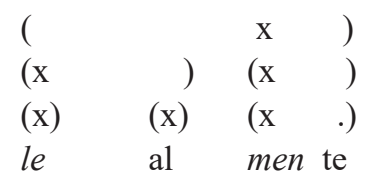


As grades anteriores mostram as etapas de aplicação da Regra do Mova X, de Hayes (1995), utilizada quando há um choque acentual no momento de formação de uma determinada estrutura na língua. Na etapa $b$, linha 1 , constata-se o choque acentual entre a última sílaba da base e a sílaba men de -mente. A fim de resolver o choque entre acentos, verifica-se na etapa c, linha 1 , o deslocamento do acento da base para uma sílaba mais à esquerda da palavra.

Foi visto que tanto as ocorrências adverbiais que mantêm o acento da base como as que deslocam apresentam em sua formação duas palavras fonológicas distintas, com acentos independentes. Na próxima seção, serão apresentados vários argumentos que comprovam a existência de duas palavras prosódicas distintas na estrutura dos advérbios em - mente.

Outro fato que permite afirmar que tais advérbios apresentam $\omega$ diferentes é o tipo de pé métrico que se observa nas ocorrências adverbiais, sobretudo com relação ao elemento -mente, cujo estatuto sufixal pode ser questionado. No caso deste estudo, observa-se que as bases formadoras dos advérbios e o elemento mente apresentam cada uma delas um pé e, consequentemente, um acento, como mostra o exemplo a seguir:

(18) fremosa mente

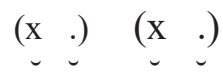

O tipo de pé observado, tanto das bases quanto de mente, é o troqueu moraico, pé canônico do português, inclusive do PA (MASSINI-CAGLIARI, 1995). O troqueu moraico é um tipo de pé que apresenta cabeça à esquerda e que leva em consideração o peso silábico, como é o caso de -mente, no qual se tem o cabeça à esquerda (na sílaba men) e, devido ao fato de a última sílaba (te) ser leve, a penúltima (men) é regularmente acentuada. No caso das bases, as que não deslocam o acento (as do grupo 1) apresentam o tipo canônico dos não verbos em PA: paroxítonas terminadas em sílaba leve. Por outro lado, as bases formadoras dos advérbios pertencentes ao grupo 2 são oxítonas terminadas por sílaba travada e, por isso, apresentam o acento nesta sílaba. Desta forma, as ocorrências dos advérbios estudados mostram que o PA era sensível à quantidade silábica na construção dos pés, isto é, o peso silábico é que determinava a posição do acento. Portanto, como foi verificado até o momento, se cada uma das partes constituintes dos advérbios em - mente forma pés separados, com acentos individuais, logo, cada uma dessas partes é uma palavra fonológica distinta.

Pode-se afirmar ainda que o deslocamento acentual ocorrido devido ao choque de acentos é similar ao que ocorre também em sintagmas. Vejamos um exemplo disso a partir do sintagma Jòrnal Hóje, proferido todos os dias pela apresentadora Sandra Annenberg, do jornal televisivo Jornal Hoje. Neste sintagma, observa-se a atribuição de dois acentos de palavra independentes: um na sílaba nal, de jornal, e outro na sílaba ho, de hoje. Ao formar o sintagma, ocorre um choque de acentos entre essas sílabas e, 
consequentemente, um deslocamento do acento da sílaba nal para a sílaba jor, como mostra o esquema a seguir:

(19)

Jornál Hóje $\rightarrow$ Jòrnal Hóje

Outros exemplos de sintagmas semelhantes ao citado anteriormente são:

(20)

computadór rápido $\rightarrow$ compùtador rápido ou còmputadór rápido

anél gránde $\rightarrow$ ànel gránde

Portanto, percebe-se que os sintagmas expostos nos exemplos (19) e (20) apresentam comportamento semelhante aos advérbios em -mente do grupo 2, uma vez que, assim como tais advérbios, os sintagmas sofrem choque acentual que é resolvido por meio do deslocamento do acento de uma das sílabas mais à direita para uma das sílabas mais à esquerda. Sendo assim, se as formas adverbiais em -mente apresentam o mesmo tipo de deslocamento acentual dos sintagmas (estruturas com dois acentos), pode-se inferir que tal fato é apenas mais um argumento para se considerar tais advérbios estruturas com acentos independentes. Contudo, deve-se ressaltar que, diferentemente dos sintagmas, os advérbios em -mente não apresentam flexão de número entre as suas partes e, devido a isso, não podem ser inseridos no grupo de sintagmas do português, mas sim dentro do grupo de estruturas com duas palavras fonológicas distintas, ou seja, palavras com acentos independentes e que podem ser classificadas como compostas, do ponto de vista prosódico.

\section{Os advérbios em -mente: estatuto prosódico}

Nesta seção, apresentam-se a descrição e análise a que se chegou sobre o estatuto prosódico das formas adverbiais em - mente, tanto no PA quanto no Português atual.

Primeiramente, são expostos aspectos da teoria prosódica capazes de descrever algumas características do elemento -mente.

Foi visto na seção dedicada à teoria da Fonologia Prosódica que Selkirk (1984), ao estudar o acento de palavra no inglês, embasa-se no conceito de afixos neutros (Neutral affixes) e afixos não neutros (Nonneutral affixes). Estes últimos sempre estão dentro das palavras, por isso são chamados também de root affixes. Por outro lado, os afixos neutros sempre estão fora dos afixos não neutros, ou seja, não se adjungem a uma base, mas sim a uma palavra, sendo denominados de word affixes, mas as palavras nem sempre estão dentro das raízes apenas dentro de outras palavras.

Tomando como base a ideia de Selkirk (1984) para os afixos do inglês, pode-se pensar em algo semelhante para -mente em português, uma vez que tal afixo poderia 
ser um afixo neutro, ou seja, é irmão da categoria palavra, pois não aparece dentro das raízes, ou seja, é uma subcategoria para categorias do tipo palavra, como é possível conferir nos exemplos abaixo, tanto para o PA quanto para o Português atual:

PA

$$
\begin{array}{ll}
\text { abertamente } & \rightarrow * \text { abertmentea } \\
\text { certamente } & \rightarrow * \text { certmentea } \\
\text { fremosamente } & \rightarrow \text { *fremosmentea } \\
\text { saborosamente } & \rightarrow \text { *saborosmentea }
\end{array}
$$

Português atual

$$
\begin{array}{ll}
\text { abertamente } & \rightarrow * \text { abertmentea } \\
\text { certamente } & \rightarrow * \text { certmentea } \\
\text { formosamente } & \rightarrow * \text { formosmentea } \\
\text { saborosamente } & \rightarrow * \text { saborosmentea }
\end{array}
$$

Com relação aos afixos neutros e não neutros, Selkirk (1984) afirma ainda que os não neutros (root affixes) estão dentro do padrão canônico de acento do inglês, uma vez que podem ser adjungidos antes da regra de atribuição de acento, ou seja, no interior da palavra. Por outro lado, os afixos neutros (word affixes) não seguem esse padrão, podendo ser adjungidos depois da aplicação da regra de acento. Isso quer dizer que a atribuição do acento nas palavras formadas por esses afixos não ocorre no interior da palavra formada, mas sim entre palavras.

Logo, pode-se pensar que o "afixo" -mente, formador dos advérbios estudados neste trabalho, ao ser um afixo neutro, irmão da categoria palavra, pode ter um domínio acentual independente e, consequentemente, ao se adjungir a bases já flexionadas (também com acentos próprios), formar elementos compostos, do ponto de vista prosódico, pois a Regra de Atribuição do Acento ocorre entre palavras prosódicas distintas, como será observado mais adiante.

Foi visto ainda que a palavra fonológica ( $\omega$ ) é o constituinte prosódico que representa a relação entre os componentes morfológicos e fonológicos. Segundo Nespor e Vogel (1986), as noções morfológicas utilizadas para discutir a formação de palavra prosódica não são as mesmas em todas as línguas. Sendo assim, dependendo da língua em estudo, o domínio para a definição de palavra prosódica leva em consideração aspectos diversos.

Uma palavra fonológica pode ter como domínio Q, ou seja, um nó sintático terminal. Mas também, segundo Nespor e Vogel (1986), pode apresentar como domínio: (a) uma raiz; (b) algum elemento identificado por critérios morfológicos e/ou fonológicos; (c) algum elemento marcado com o diacrítico [+W]; (d) qualquer elemento solto dentro de Q que faz parte da $₫$ adjacente mais próxima da raiz.

Tomando como base o conceito de domínio exposto no parágrafo anterior, podese pensar que, no caso deste estudo, o domínio pertinente poderia ser: (b) algum elemento identificado por critérios morfológicos e/ou fonológicos, uma vez que as bases formadoras dos advérbios em -mente teriam como critérios morfológicos o fato de serem adjetivas com ou sem marca de flexão de gênero e o acento em -mente teria como critério fonológico o fato de ser uma estrutura que forma um pé ${ }^{10}$ - troqueu moraico,

10 Para maiores informações sobre o pé métrico no contexto dos advérbios em -mente, conferir seção anterior, referente à análise dessas formas adverbiais à luz da teoria da Fonologia Métrica. 
como visto na seção anterior. Sendo assim, levando em consideração tal teoria do domínio de $₫$, é possível supor que os advérbios em -mente investigados por este estudo podem ser considerados elementos que são formados por partes independentes entre si, em que a Regra de Atribuição do Acento atua em domínios distintos: nas bases já flexionadas e no "sufixo" -mente. Logo, cada uma das partes pode ser considerada uma palavra fonológica distinta.

Com relação ainda ao domínio da palavra prosódica, Nespor e Vogel (1986) afirmam que as sílabas e os pés podem ser reajustados em $\omega$. Apesar de ser afirmado que não há isomorfismo entre estrutura prosódica e estrutura morfossintática, observa-se em algumas línguas tal isomorfismo entre palavra prosódica e palavra morfológica (W). Constatou-se, com a coleta dos dados que, no caso da maioria das bases dos advérbios em -mente, isso acontece também, tanto em PA como em PB:

$$
\begin{aligned}
& {\left[[\text { aberta }]_{\mathrm{W}}\right]_{\mathrm{PW}}} \\
& {\left[[\text { fremosa }]_{\mathrm{W}}\right]_{\mathrm{PW}}} \\
& {\left[[\text { leal }]_{\mathrm{W}}\right]_{\mathrm{PW}}} \\
& {\left[[\text { natural }]_{\mathrm{W}}\right]_{\mathrm{PW}}}
\end{aligned}
$$

As bases expostas nos exemplos anteriores podem mostrar a independência fonológica existente nelas, uma vez que, se tais bases são palavras fonológicas, torna-se evidente a presença de um acento primário naquelas e, como visto na seção sobre palavra prosódica, um dos critérios de delimitação de palavra prosódica é a presença de um acento de palavra. Logo, pode-se inferir que as bases adjetivas formadoras dos advérbios em - mente, quer sejam femininas, quer sejam sem flexão aparente de gênero, eram em PA e são em PB portadoras de um acento próprio e, consequentemente, independentes do ponto de vista prosódico, visto que são por si sós palavras fonológicas.

Como já exposto, a Palavra Prosódica (®) pode subdividir-se, segundo Vigário (2003), em dois tipos: a Palavra Prosódica Minima - a qual é dotada de apenas um acento primário e composta por estruturas incorporadas (palavras com sufixos ou hospedeiros mais enclíticos) ou estruturas adjungidas (palavras com prefixos ou hospedeiros mais proclíticos) - e a Palavra Prosódica Máxima ou Composta - a qual é formada por duas Palavras Prosódicas (caso das palavras compostas que não formam um sintagma fonológico), entretanto tem apenas um elemento proeminente que carrega a proeminência principal desse domínio.

No caso dos advérbios estudados, observa-se que tais formas adverbiais apresentam a palavra prosódica máxima ou composta, mais precisamente o subtipo II: palavras derivadas com sufixos que constituem domínios de acento independentes de sua base, como "francamente" [[franca]W[mente]W]PWMAX, como mostra a representação a seguir, extraída de Vigário (2003, p.227): 
(23)

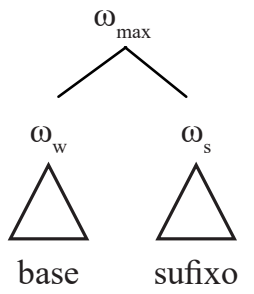

Para o PA e o PB, constata-se a mesma estrutura proposta acima por Vigário (2003, p.227):

(24)

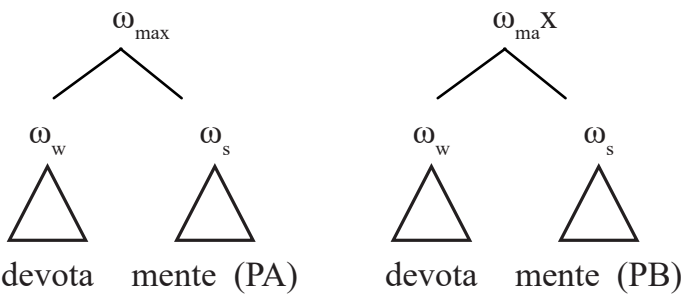

$(25)$

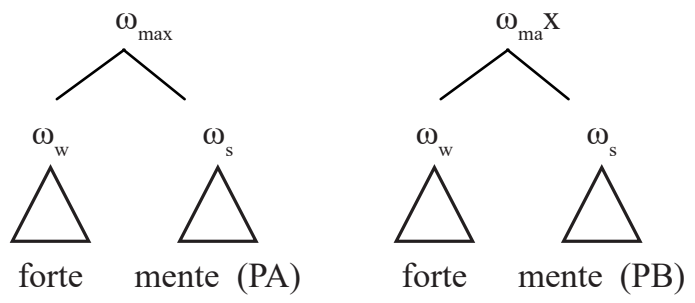

Os exemplos anteriores mostram que, na formação dos advérbios em -mente no Português, tem-se dentro da Palavra Prosódica Máxima um elemento mais proeminente localizado à direita dessas formas, no caso - mente. Com isso, pode-se supor que esse elemento é portador do acento de palavra ou o acento principal. Observa-se ainda que a palavra prosódica máxima traz uma proeminência mais fraca, representada por $\omega_{w}$, que se encontra nas bases formadoras desses advérbios.

Ainda sobre palavra fonológica, Vigário (2007) afirma que, quando há tal relação de dominância entre duas palavras prosódicas, tem-se o que a autora denomina de Grupo de Palavra Prosódica. Dentre os constituintes que integram este grupo, citam-se: palavras derivadas com sufixos que formam domínios de acento lexical independentes da sua base, palavras derivadas com prefixos acentuados, compostos morfológicos, 
compostos morfossintáticos, alguns compostos sintáticos, estruturas mesoclíticas, siglas, pronúncia de sequências de letras, sequências de letras e números e certas sequências de numerais e nomes. ${ }^{11}$

Embasada nesta proposta de Vigário (2007) sobre Grupo de Palavra Prosódica, Ferreira (2012) propõe uma divisão dos afixos do Português em afixos primários e afixos secundários. Segundo a autora (FERREIRA, 2012), os afixos secundários, como -mente só podem ser adjungidos após os sufixos flexionais. Por exemplo, em uma ocorrência como fremosamente, constata-se que o sufixo flexional de gênero aparece antes do sufixo -mente: fremos-a-mente. Esse mesmo raciocínio vale para os advérbios formados por bases não femininas, como lealmente, em que o morfema flexional zero (ø) para gênero não ocorre no final da palavra, mas sim antes da adjunção do sufixo -mente: leal- $\varnothing-m e n t e$. Este fato mostra que não estamos diante de um processo de derivação sufixal, mas sim diante de palavras independentes e que tendem a ser classificadas como compostas, do ponto de vista fonológico.

Observaram-se até o momento dois conceitos importantes relacionados à palavra prosódica e que servem de diagnóstico para a delimitação deste constituinte prosódico: o domínio e a atribuição do acento de palavra. Além desses, há outros diagnósticos para a delimitação de palavra prosódica como: as generalizações fonotáticas, o apagamento sob identidade, clipping, requerimento de palavra mínima e silabificação. Ressaltase que, no caso desta pesquisa, dentre os critérios para delimitação de $\omega$ citados anteriormente, testamos apenas o critério de apagamento sob identidade, pois outros fenômenos puramente fonológicos não foram encontrados na formação dos advérbios em -mente no PA.

O apagamento sob identidade é um processo no qual um elemento dentro de palavras complexas em estruturas coordenadas pode ser apagado sem trazer prejuízos ao entendimento da estrutura. Se esse elemento pode ser omitido em uma determinada sequência, pode evidenciar que estamos diante de uma palavra prosódica independente. A respeito disso, grande parte da literatura especializada (BECHARA, 2005; BASÍLIO, 2006; COSTA, J., 2008) afirma ser -mente no PB um elemento passível de apagamento em estruturas como: Ele chegou vagarosa e tranquilamente. Para o PA, não foi possível aplicar este critério às formas adverbiais mapeadas, uma vez que, apesar de os dados mapeados nas cantigas medievais fornecerem uma estrutura coordenativa, o primeiro

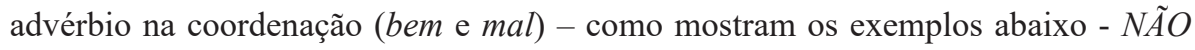
apresenta a terminação - mente (*malmente e *benmente), fato este que nos leva a não utilizar este critério para a definição de elementos autônomos na formação dos advérbios em -mente no período arcaico da língua portuguesa.

11 Massini-Cagliari (1992, p.130) mostra que a pronúncia dessas sequências forma compostos no PB. 
(26)

Cantiga de Santa Maria 192, versos 46-48

"Ena Groriosa,

e a razoar

mal e soberviosamente..."

(METTMANN, 1988, p.220).

(27)

Cantiga de Santa Maria 305, versos 72-73

"[...] per que sempre viviria

ben e avondadamente..."

(METTMANN, 1989, p.108).

(28)

Cantiga de Santa Maria 335, versos 51-52

"[...] mas ele per sy fez as papas

mui ben e apostamente..."

(METTMANN, 1989, p.176).

(29)

Cantiga de Santa Maria 369, versos 47-48

"[...] e pagaron seus dynneyros

ben e muy compridamente..."

(METTMANN, 1989, p.251).

Até o momento, a presente seção descreveu e discutiu evidências que levam a afirmar que os advérbios em -mente, tanto em PA quanto em PB, são formados por palavras independentes, do ponto de vista prosódico. Porém, deve-se destacar que, dentre as ocorrências mapeadas, há uma que chamou atenção devido à sua estrutura. Trata-se da forma bõa mente. Todas as vezes que tal ocorrência foi mapeada, constatouse juntamente a ela a presença da preposição de, como mostra exemplo a seguir, fato este que não ocorreu com as outras formas adverbiais mapeadas. 
(30)

Cantiga de Santa Maria 67, versos 26-30

“E vẽo pera el logo | manss' e en bon contenente,

e disse: «Sennor, querede | que seja vosso sergente,

e o serviço dos pobres | vos farei de bõa mente,

pois vejo que vos queredes | e fazedes y bondade;

A Reynna gloriosa | tant' é de gran santidade..."

(METTMANN, 1986, p.226).

Observando o exemplo (30), percebe-se que a expressão de bõa mente tem como significado de boa vontade, fato este que mostra já no nível semântico que esta forma não corresponde a um advérbio de modo.

Tomando como base Toneli (2009), pode-se inferir que a presença da preposição de (uma palavra funcional e, portanto, prosodizada como clítico, já que não forma um pé e não recebe acento primário) pode indicar que estamos diante de um sintagma fonológico. Ao observar atentamente a estrutura acima, pode-se classificar o de da forma de boa mente como um clítico livre, pois tal palavra é diretamente ligada ao sintagma fonológico, não sendo adjungida à palavra prosódica ou mesmo incorporada a ela, como mostra a estrutura a seguir:

(func (lex)PW )PPh

(de (bõa)PW (mente)PW)PPh

Retomando Toneli (2009), constata-se que há algumas Restrições de Alinhamento da Palavra Prosódica e, partindo de tais restrições, pode-se afirmar que para delimitar uma Palavra Prosódica, sua fronteira esquerda (L) deve coincidir com a fronteira esquerda de alguma palavra lexical (Lex). Considerando o estudo da autora, a diferença entre uma palavra lexical e uma palavra funcional é que as palavras funcionais não têm o estatuto de Palavra Prosódica na representação fonológica. Sendo assim, pode-se pensar que no caso da estrutura de bõa mente a preposição de não teria o estatuto de palavra prosódica, porque sendo uma palavra funcional, sua fronteira não está alinhada com a fronteira da palavra prosódica boa e, consequentemente, tal estrutura poderia ser considerada um sintagma fonológico.

Ao término desta seção, foi possível inferir que tanto as ocorrências de advérbios em -mente no PA quanto as no PB apresentam algumas evidências para serem classificadas como formas independentes, autônomas. Uma delas diz respeito ao fato de essas formas apresentarem na maioria dos casos mapeados a seguinte estrutura morfológica: base adjetiva feminina + -mente. A partir disso, tomando como base a ideia de Selkirk (1984) para os afixos do inglês, pode-se pensar em algo semelhante para-mente em português, uma vez que tal afixo poderia ser um afixo neutro, ou seja, é 
irmão da categoria palavra, pois não aparece dentro das raízes; é uma subcategoria para categorias do tipo palavra. Sendo assim, pode ter um domínio acentual independente e, consequentemente, ao se adjungir a bases já flexionadas (também com acentos próprios), formar elementos compostos, do ponto de vista prosódico, uma vez que a Regra de Atribuição do Acento ocorre entre palavras prosódicas distintas.

Dessa forma, pode-se supor que os advérbios em -mente investigados por este estudo são considerados elementos formados por partes independentes entre si, em que a Regra de Atribuição do Acento atua em domínios distintos: nas bases já flexionadas e no "sufixo" -mente. Logo, cada uma das partes pode ser considerada uma palavra fonológica distinta, cada uma com um acento próprio.

\section{Considerações finais}

$\mathrm{O}$ presente artigo procurou apresentar evidências sobre a atribuição do acento nas formas adverbiais em -mente no PA e no PB, a fim de defini-las como formas compostas, do ponto de vista prosódico. Uma delas diz respeito ao fato de essas formas apresentarem na maioria dos casos mapeados a seguinte estrutura morfológica: base adjetiva feminina + -mente. A partir disso, tomando como base a ideia de Selkirk (1984) para os afixos do inglês, foi possível pensar em algo semelhante para-mente em português, uma vez que tal afixo seria um afixo neutro, ou seja, não aparece dentro das raízes. Sendo assim, pode ter um domínio acentual independente e, consequentemente, ao se adjungir a bases já flexionadas (também com acentos próprios), formar elementos compostos, do ponto de vista prosódico, uma vez que a Regra de Atribuição do Acento ocorre entre palavras prosódicas distintas.

Para finalizar, é possível afirmar que este estudo contribuiu, em um âmbito mais geral, para mostrar se os processos que ocorrem na formação de palavras da língua portuguesa se modificaram ou se mantiveram, o que pode auxiliar para esclarecer fatos da estrutura linguística atual.

\section{Agradecimentos}

A realização do estudo apresentado neste artigo não seria possível sem a colaboração de algumas pessoas e instituições, a começar pelo Grupo de Pesquisa Fonologia do Português: Arcaico \& Brasileiro. Além disso, é preciso agradecer à FAPESP (Fundação de Amparo à Pesquisa do Estado de São Paulo, Processo número 2011/18933-8), órgão financiador da pesquisa. 
ABREU-ZORZI, T.; MASSINI-CAGLIARI, G. Stress assignment of -mente adverbs in Portuguese: discussion of prosodic and rhythmic aspects. Alfa, São Paulo, v.62, n.2, p.381-408, 2018.

- ABSTRACT: This article aims to present a discussion about the prosodic behavior of adverbs in -mente in Archaic Portuguese (AP) and Brazilian Portuguese (BP) under the Prosodic and Metrical Phonology bias. For the description of the prosodic status of these adverbs, especially in AP, a corpus composed of 420 cantigas [a genre of poetry] in praise of the Virgin Mary, known as Cantigas de Santa Maria (CSM), and 1251 secular cantigas (510 cantigas de amigo, 431 cantigas de escárnio e maldizer and 310 cantigas de amor). On the other hand, a part of the database from "Corpus Online do Português" [Online Corpus of the Portuguese Language], prepared jointly by researchers Michael Ferreira, from Georgetown University, and Mark Davies, from Brigham Young University, was elected as study corpus of the BP. From the collection and analysis of the adverbial forms ending in-mente in the corpora, it has been concluded that, from the prosodic perspective, the adverbial forms ending in-mente are compounds (one lexical stress and one secondary stress) in both AP and BP, since such adverbs may be considered elements formed of independent parts among themselves, where the Stress Assignment Rule operates in different domains: in bases already inflected and in the "suffix" ending in -mente.

- KEYWORDS: Adverbs ending in -mente. Stress assignment. Prosody. Archaic Portuguese. Brazilian Portuguese.

\section{REFERÊNCIAS}

ABREU-ZORZI, T. H. O estatuto prosódico dos advérbios em -mente: um estudo comparativo entre Português Arcaico e Português Brasileiro. 2016. 228f. Tese (Doutorado em Linguística) - Faculdade de Ciências e Letras, Universidade Estadual Paulista, Araraquara, 2016.

BASÍLIO, M. Formação e classes de palavras no português do Brasil. São Paulo: Contexto, 2006.

BECHARA, E. Moderna Gramática Portuguesa. 37.ed. Rio de Janeiro, Lucerna, 2005.

CHOMSKY, N.; HALLE, M. The sound pattern of English. New York: Harper \& Row, 1968.

COLLISCHONN, G. Acento secundário em português. Letras de Hoje, Porto Alegre, v.29, n.4, p.43-53, dez. 1994.

COSTA, D. S. da. A interface música e linguística como instrumental metodológico para o estudo da prosódia do Português Arcaico. 2010. 200f. Tese (Doutorado 
em Linguística) - Faculdade de Ciências e Letras, Universidade Estadual Paulista, Araraquara, 2010.

COSTA, D. S. da. Estudo do acento lexical no Português Arcaico por meio das Cantigas de Santa Maria. 2006. 163f. Dissertação (Mestrado em Linguística) Faculdade de Ciências e Letras, Universidade Estadual Paulista, Araraquara, 2006.

COSTA, J. O advérbio em Português Europeu. Lisboa: Colibri, 2008.

DAVIES, M.; FERREIRA, M. Corpus do Português: 45 million words, 1300s-1900s. Georgetown: Universidade de Georgetown, 2006. Disponível em: <http://www. corpusdoportugues.org/x.asp>. Acesso em: 05 jan. 2017.

FERREIRA, M. L. S. Contributos para uma definição de palavra fonológica. 2012. 211f. Dissertação (Mestrado em Linguística) - Faculdade de Letras da Universidade do Porto, Porto, 2012.

HAYES, B. Metrical stress theory: principles and case studies. Chicago; London: University of Chicago Press, 1995.

LAPA, M. R. Cantigas d'Escarnho e Mal Dizer dos Cancioneiros Medievais Portugueses: edição crítica e vocabulário. 4.ed ilustrada. Lisboa: João Sá da Costa, 1998. Originalmente publicado em 1965.

LEE, S.-H. Morfologia e fonologia lexical do Português. 1995. Tese (Doutorado em Lingüística) - Instituto de Estudos da Linguagem, Universidade de Campinas, Campinas, 1995.

LIBERMAN, M. The intonational system of English. 1975. 324 f. Dissertation (Doctoral of Linguistics) - Massachusetts Institute of Technology, Cambridge, MA, 1975. Disponível em: <http://www.ai.mit.edu/projects/dm/theses/liberman75.pdf>. Acesso em: 06 dez. 2015.

LIBERMAN, M.; PRINCE, A. S. On stress and linguistc rhythm. Linguistic inquiry, Cambridge, n.8, p.249-336, 1977.

LOPES, J. R. Literatura de Cordel: antologia. Fortaleza: BNB, 1982.

MASSINI-CAGLIARI, G. A música da fala dos trovadores: desvendando a prosódia medieval. São Paulo: Ed. da Unesp, 2015.

MASSINI-CAGLIARI, G. A música da fala dos trovadores: estudos de Prosódia do Português Arcaico, a partir das cantigas profanas e religiosas. 2005. 348f. Tese (Livre-Docência) - Faculdade de Ciências e Letras, Universidade Estadual Paulista, Araraquara, 2005.

MASSINI-CAGLIARI, G. Do poético ao lingüístico no ritmo dos trovadores: três momentos da história do acento. Araraquara: FCL, Laboratório Editorial, UNESP; São Paulo: Cultura Acadêmica, 1999. 
MASSINI-CAGLIARI, G. Cantigas de amigo: do ritmo poético ao linguístico: um estudo do percurso histórico da acentuação em Português. 1995. 300f. Tese (Doutorado em Linguística) - Instituto de Estudos da Linguagem, Universidade de Campinas, Campinas, 1995.

MASSINI-CAGLIARI, G. Acento e ritmo. São Paulo: Contexto, 1992.

MASSINI-CAGLIARI, G.; CAGLIARI, L. C. Fonética. In: MUSSALIM, F.; BENTES, A. C. (Org.). Introdução à Linguística: domínios e fronteiras. São Paulo: Cortez, 2001. v.1, p.105-146.

MASSINI-CAGLIARI, G.; CAGLIARI, L. C. De sons de poetas ou estudando fonologia através da poesia. Revista da Anpoll, São Paulo, n.5, p.77-105, 1998.

MATTOS E SILVA, R. V. O Português Arcaico: fonologia, morfologia e sintaxe. São Paulo: Contexto, 2006

METTMANN, W. (Ed.). Cantigas de Santa María (cantigas 261 a 427): Alfonso X, el Sabio. Madrid: Castalia, 1989. v.3.

METTMANN, W. (Ed.). Cantigas de Santa María (cantigas 101 a 260): Alfonso X, el Sabio. Madrid: Castalia, 1988. v.2.

METTMANN, W. (Ed.). Cantigas de Santa María (cantigas 1 a 100): Alfonso X, el Sabio. Madrid: Castalia, 1986. v.1.

MICHAËLIS DE VASCONCELOS, C. Cancioneiro da Ajuda: edição crítica e comentada. Lisboa: Imprensa Nacional: Casa da Moeda, 1904.

NESPOR, M.; VOGEL, I. Prosodic Phonology. Dordrecht: Foris Publications, 1986.

SELKIRK, E. O. Phonology and Syntax: the relation between sound and structure.

Cambridge: The Mit Press, 1984.

SELKIRK, E. O. On prosodic structure and its relation to syntactic structure. Bloomington: Indiana University Linguistics Club, 1980.

SIEGEL, D. Topics in English Morphology. 1974. 194f. Dissertation (PhD of Linguistics) - Massachusetts Institute of Technology, Cambridge, 1974. Disponível em: $<$ http://www.ai.mit.edu/projects/dm/theses/siegel74.pdf >. Acesso em: 06 dez. 2015.

TONELI, P. M. A palavra prosódica no Português Brasileiro: o estatuto prosódico das palavras funcionais. 2009. 177f. Dissertação (Mestrado em Linguística) - Instituto de Estudos da Linguagem, Universidade Estadual de Campinas, Campinas, 2009.

VIGÁRIO, M. O lugar do grupo clítico e da palavra prosódica composta na hierarquia prosódica: uma nova proposta. In: LOBO, M.; COUTINHO, M. A. (Org.). ENCONTRO NACIONAL DAASSOCIAÇÃO PORTUGUESA DE LINGÜÍSTIC, 22., 2007, Liboa. Textos seleccionados. Lisboa: Colibri Artes Gráficas, 2007. p.673-688. 
VIGÁRIO, M. Quando meia palavra basta: Apagamento de palavras fonológicas em estruturas coordenadas. In: CASTRO, I.; DUARTE, I. (Colab.). Razões e emoção: miscelânia de estudos em homenagem a Maria Helena Mira Mateus. Lisboa: Colibri, 2003. v.2, p.415-435.

VIGÁRIO, M. The prosodic word in European Portuguese. 2001. 440f. Dissertation (PhD of Linguistics) - Faculdade de Letras da Universidade de Lisboa, Universidade de Lisboa, Lisboa, 2001.

Recebido em 9 de outubro de 2017

Aprovado em 13 de fevereiro de 2018 